\title{
Molecular Dynamics Simulations and QM/MM Studies of the Reactivation by 2-PAM of Tabun Inhibited Human Acethylcolinesterase
}

\author{
Arlan da Silva Gonçalves, *,a Tanos C. C. França, ${ }^{b}$ \\ José D. Figueroa-Villar ${ }^{b}$ and Pedro G. Pascuttic \\ ${ }^{a}$ Rua Sete de Setembro, 117, Centro, 25020-190 Duque de Caxias-RJ, Brazil \\ ${ }^{b}$ Seção de Engenharia Química, Instituto Militar de Engenharia, Praça General Tibúrcio, 80, \\ 22290-270 Rio de Janeiro-RJ, Brazil \\ 'Instituto de Biofísica Carlos Chagas Filho, CCS, Avenida Carlos Chagas Filho, 373, Bloco D, \\ Sala D1-030, Ilha do Fundão, Universidade Federal do Rio de Janeiro, \\ 21941-900 Rio de Janeiro-RJ, Brazil
}

\begin{abstract}
A elucidação das rotas de reativação da acetilcolinesterase humana (HuAChE) inibida por organofosforados é de crucial importância para o desenvolvimento de antídotos eficientes contra a intoxicação causada por agentes de guerra química. Com o objetivo de contribuir para uma melhor compreensão do mecanismo de reativação, foram aplicadas neste trabalho simulações de dinâmica molecular (DM) clássica para estudar as interações entre a pralidoxima e aminoácidos do sítio ativo da HuAChE inibida pelo agente neurotóxico tabun. Além disso, métodos híbridos de mecânica quântica/mecânica molecular (QM/MM) foram usados para propor um mecanismo de reativação para a enzima inibida. Os resultados mostraram que a DM clássica manteve a pralidoxima no interior do sítio ativo da enzima, em uma região favorável à ocorrência de uma possível reação de desfosforilação, que foi confirmada por métodos de $\mathrm{QM} / \mathrm{MM}$, levando à proposta de um mecanismo de reativação, energeticamente favorável.
\end{abstract}

The elucidation of the reactivation routes of human acetylcholinesterase (HuAChE) inhibited by organophosphorous compounds is of crucial importance to the development of efficient antidotes against poisoning by chemical warfare agents. In order to contribute to a better understanding of the reactivation mechanism, we applied, in this work, classical molecular dynamics (MD) simulations to study the interactions between pralidoxime and the active site's amino acids of HuAChE inhibited by the neurotoxic agent tabun. Further, quantum mechanical/molecular mechanical (QM/MM) hybrid methods were used to propose a reactivation mechanism for the inhibited enzyme. The results showed that the classic MD kept pralidoxime inside the enzyme's active site, in a favorable region to the occurrence of possible reactions of dephosphorilation, which were confirmed by QM/MM methods, and lead to the proposition of an energetically favorable mechanism of reactivation.

Keywords: QM/MM studies, acethylcolinesterase, molecular dynamics, pralidoxime

\section{Introduction}

The neurotoxic agents are esters of the phosphoric acid able to inhibit irreversibly the enzyme acetylcholinesterase (AChE) by binding covalently to a serine residue (Ser203 in $\mathrm{HuAChE}$ ) of its active site, considered very important to the hydrolysis of acetylcholine, usually performed by AChE. These agents are very toxic to human beings and

*e-mail: arlansgoncalves@gmail.com have been synthesized and stockpiled as chemical warfare agents since $1937 .{ }^{1}$

The inhibition of AChE by the neurotoxic agents is believed to happen according to the two general steps illustrated in Figure 1. In the first step the $\mathrm{O}$ atom of serine forms a bond with the $\mathrm{P}$ atom of the agent, releasing the $\mathrm{X}$ group ( $\mathrm{X}$ is usually a $\mathrm{CN}$ or $\mathrm{F}$ group) and leading to the inhibited enzyme. The second step is the releasing of the group $\mathrm{R}_{1}$ leading to the aged enzyme. Before aging, the inhibition reaction can be reverted if a nucleophile, like an 
oxime, is able to attack the P group of the neurotoxic agent and remove it from the active site, reactivating the enzyme (see Figure 1). Literature has reported several oximes able to perform this reactivation reaction but did not report yet an universal oxime able to reactivate $\mathrm{AChE}$ inhibited by any neurotoxic agent. Besides, there are some neurotoxic agents impossible to be combated by any known oxime. This happens because the reactivation mechanism of Figure 1 is not fully understood yet ${ }^{2}$ and several aspects need to be elucidated, like the exact orientation of the phosphoryl bond inside the active site, the suitable oxime's charge, the most appropriated angles for attacking the phosphylated serine, the influence of the oxime's isomery, and, also, the actual chemical environment around the oxime group inside the inhibited AChE, that still remains unknown. ${ }^{1-10}$

The computational facilities available today has permitted the simulation of the AChE enzymatic behavior in order to improve the understanding of the minor steps involved in the mechanism of Figure 1. New methodological advances permit now to simulate more realistically inter and intra molecular interactions along with the chemical reactions involved and the breaking and forming of bonds. This has been possible thanks to the employment of molecular dynamics techniques using quantum, semi-empirical or even mixed methods, i.e., methods using, at the same time, quantum mechanical and classical mechanical approaches. ${ }^{11-18}$

In the present work we improved a former MD study of pralidoxime (2-PAM) and HuAChE inhibited by the neurotoxic agent tabun ${ }^{5}$ and used the results to propose a new QM/MM methodology useful to the simulation of the reaction between oximes and HuAChE inhibited by neurotoxic agents. The quantum part of the system was composed of 142 atoms and involved the HuAChE catalytic triad (Ser203, His447 and Glu334), the neurotoxic agent tabun and some additional aminoacid residues of the active site which are also considered important to the reactivation reaction. The classical part was composed by the remaining residues, the solvent atoms and the counter ions. This method was further validated and used to propose a reactivation mechanism for the HuAChE reactivation by pralidoxime.

\section{Methodology}

\section{Molecular dynamics simulation}

The initial coordinates of the complex HuAChEinhibitor-oxime used for the classic simulation were the ones proposed in a former work for HuAChE covalently bound to GA and complexed with 2-PAM. ${ }^{5}$ This system was submitted to MD simulations steps using the GROMACS 3.3.3 ${ }^{19}$ package with the OPLS/AA ${ }^{20,21}$ force field. Parameters like bonds, angles, dihedrals, improper dihedrals, third neighbors and spring constants for 2-PAM and GA, had to be manually introduced into the OPLS/AA ${ }^{20,21}$ topology file since this force field does not contain parameters for molecules different from amino acids and nucleotides. Charges for the ligands were calculated by the CHELPG method ${ }^{22}$ using the softwares GAMESS US ${ }^{23}$ and Hartree-Fock with basis set $6-31 \mathrm{G}^{* * *}$. The system was placed inside a cubic box containing 27856 water molecules TIP4P, ${ }^{24}$ with periodic boundary conditions (PBC) and counter ions, in order to neutralize the total charge, totalizing 119711 atoms. The system's energy was minimized, sequentially, by the steepest descent, with and without positions restriction (PR) for the heavy atoms, conjugate gradients and quasi Newton-Raphson methods ${ }^{25,26}$ until a final energy of $1 \mathrm{kcal} \mathrm{mol}^{-1} \AA^{-1}$. After minimization the system was submitted to MD simulations in two steps: first there were performed 500 ps of simulation at $310 \mathrm{~K}, 1$ bar of pressure and PR for the heavy atoms of the protein complexed with GA and all atoms of 2-PAM, in order to accommodate the water molecules in the system. Then a full MD simulation of $6.5 \mathrm{~ns}$ without restriction was performed at $310 \mathrm{~K}, 1$ bar of pressure, integration time



Figure 1. General mechanism of action of the oximes. 
of 2 fs, PME (particle Mesh Ewald) ${ }^{27,28}$ for electrostatic interactions and cut off of $10 \AA$ for the real space and for the short range interactions.

Before the $\mathrm{QM} / \mathrm{MM}$ studies, it was necessary to compile a computational package to merge two programs, MOPAC with RM1 and GROMACS. The procedure adopted to this task is described in supplementary information. We did not notice yet the compilation GROMACS/RM1 for QM/MM studies in literature and believe that it has been done for the first time in the present work.

\section{QM/MM studies}

After compilation, the GROMACS+MOPAC+RM1 package was tested using the last frame of the PR MD simulation described above for the system $\mathrm{HuAChE} / 2$ PAM/GA. For this task, only the 2-PAM atoms were labeled as quantic atoms $s^{5}$ and the hybrid energy optimizations were performed using the RM1 method after comparison with AM1 and PM3.

The protonation states of the HuAChE residues: Asp, Glu, His, Cys, Tyr, Lys and Arg for the QM/MM studies were determined in the PROPKA server ${ }^{29,30}$ employing empiric parameters to calculate the $\mathrm{pK}$ of these residues in different environments. The parameters considered in this analysis are $\mathrm{H}$ bonds, electrostatic interactions and dehydration effects and the basic principle to the calculation of $\mathrm{pK}$ by this server is based on equations 1 and 2:

$\mathrm{pK}_{\mathrm{a}}=\mathrm{pK}_{\text {model }}+\Delta \mathrm{pK}_{\mathrm{a}}$

$\Delta \mathrm{pK}_{\mathrm{a}}=\Delta \mathrm{pK}_{\text {dehydration }}+\Delta \mathrm{pK}_{\text {hbonds }}+\Delta \mathrm{pK}_{\text {eletrostatic }}$

Where, $\mathrm{pK}_{\text {model }}$ is the $\mathrm{pK}_{\mathrm{a}}$ of the residues in solution and $\Delta \mathrm{pK}_{\mathrm{a}}$ the sum of the components referring to the dehydration, $\mathrm{H}$ bonds and electrostatic effects.

The selection and characterization of the quantum atoms were performed by the visualization of the system $\mathrm{HuAChE} / 2-\mathrm{PAM} / \mathrm{GA}$ with the software PyMOL ${ }^{31,32}$ followed by the selection of 2-PAM, the amino acid residues of the catalytic triad of HuAChE [Ser203 bonded to GA (Ser203-GA), His447 and Glu334] and the neighboring residues: Trp86, Tyr124, Glu202, Ala204, Tyr337 and Glu450, considered important to the mechanism of HuAChE reactivation (Figure 1). The ONIOM approximation, ${ }^{33,34}$ inserted in the gmxmop.f MOPAC source code, in which the classic moiety is separated from the quantum one by the link atom (LA), was employed between the carbon atoms $\alpha$ and $\beta$ of each amino acid cited above in order to treat quantically only the side chains of those residues. These atoms plus 2-PAM constituted the semi-empirical moiety of the system, totalizing 142 atoms, and are shown in Figure 2. The remaining atoms of the protein, the counter ions and the solvent molecules constituted the classic moiety.

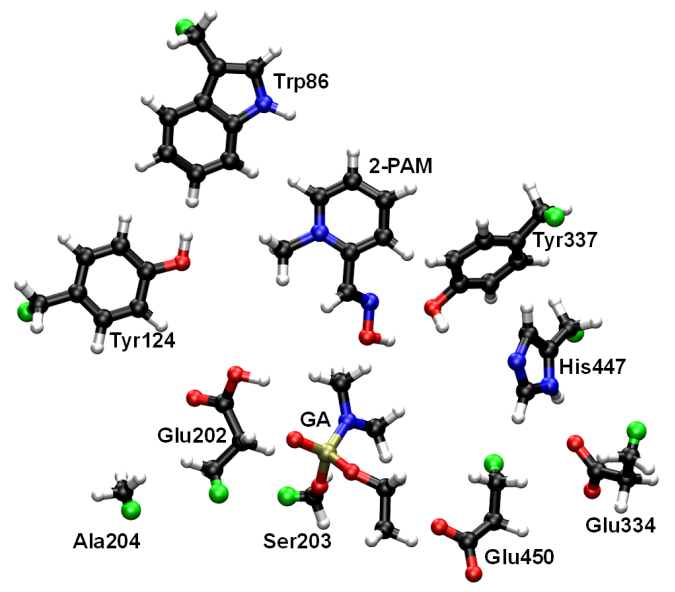

Figure 2. Quantum atoms of the system. Link atoms (LA) are shown in green.

The initial condition for the QM/MM simulation was the frame of the classic simulation where 2-PAM is in the closest position related to GA and His447 and the simulations were performed in steps according to the path of the reactivation reaction. First there were performed 03 steps of $50 \mathrm{ps}$ without distance restriction followed by 12 steps of 5 ps with distance restriction between atoms, totalizing $210 \mathrm{ps}$ of QM/MM simulation. All these steps were performed at $310 \mathrm{~K}$ and $1 \mathrm{bar}$ of pressure and the integration step was $1 \mathrm{fs}$ or half of the integration step used in the classic simulation, in order to make possible to deal with the bond vibrations between $\mathrm{C}$ and $\mathrm{H}$, usually unnoticeable at $2 \mathrm{fs}$. This method is known as linear transit search (LT Search) and has already been applied successfully by Groenhof and co-workers. ${ }^{31-33}$

Transition state and intrinsic reaction coordinate characterization

After the QM/MM simulation it was necessary to characterize the possible transition states (TSs) of each step like true saddle points. This task was performed, using the same methodology described in a former work, ${ }^{6}$ by optimizing the possible TSs only to the quantum regions for each reaction step. After optimization, the hessian matrix for each reaction step was calculated and, in order to verify if there were connections among reactants, TS and products, we calculated the intrinsic reaction coordinate (IRC) using the software MOPAC and the method RM1. The visualization of results was performed with Spartan 08®. 


\section{Results and Discussion}

\section{Molecular dynamics of the HuAChE/2-PAM/GA complex}

As mentioned in the methodology section, the initial coordinates for the classic MD simulation were the ones proposed to the system $\mathrm{HuAChE} / \mathrm{GA} / 2$-PAM with 2-PAM docked at $3.91 \AA$ of Ser203-GA obtained from a former work. ${ }^{5}$ After the minimization and PR MD steps this frame was submitted to further $6.5 \mathrm{~ns}$ of MD simulation. The total energy and root mean squared displacement (RMSD) analysis plots presented in Supplementary Information (SI) (Figures S1 and S2, respectively), state the stability of this simulation.

The quadratic regression applied to the total energy values (red line in Figure S1) show that the complex HuAChE/GA/2-PAM stabilizes at about 3 ns of simulation, suggesting structural stabilization along the remaining $3.5 \mathrm{~ns}$. The temporal RMSD calculation of the system was performed related to the first frame of simulation in order to check qualitatively when the system's stabilization occurs. The plot in Figure S2 shows that from 2 ns on the system position oscillates between 1.8 and $2.4 \AA$ A suggesting a good dynamic stabilization.

Analysis of the distance variation between the $\mathrm{O}$ atom of 2-PAM and the $\mathrm{P}$ atom of GA showed that from $3 \mathrm{~ns}$ of MD simulation, this distance stabilized around 4 and $5 \AA$ as shown in Figure S3 (SI). This result shows that 2-PAM have the tendency to remain at an interacting distance of GA.

In order to check which residues could interact with 2-PAM, we selected in the frame at $3.0 \mathrm{~ns}$ of MD simulation the residues inside a radius of $5.0 \AA$ from each 2-PAM atom. Then we separated the ones that could be contributing to the stabilization of 2-PAM by hydrophobic interactions or $\mathrm{H}$ bonds. The selected residues according to this criterion were Ser203-GA, Trp86, Tyr124, Tyr337 and His447. Considering that in the frame at $3.0 \mathrm{~ns}$ of simulation, 2-PAM was flanked by Trp86 and Tyr124, the distances among the atoms $a_{1}-a_{2}$ and $a_{3}-a_{4}$ shown in Figure 3 were monitored along the simulation in order to check if 2-PAM remained stable in this position and which possible interactions could be occurring with these two residues.

Results in SI, Figure S4, show that the distance between the $\mathrm{O}$ atom of Tyr124 $\left(\mathrm{a}_{3}\right)$ and the positive $\mathrm{N}$ of 2-PAM $\left(\mathrm{a}_{4}\right)$ stabilizes at $3.7 \pm 0.3 \AA$, suggesting possible electrostatic interactions between Tyr124 and 2-PAM after $3.0 \mathrm{~ns}$ of simulation. Besides it was also observed that the distance between the $\mathrm{C}$ atom of the 2-PAM aromatic ring $\left(a_{1}\right)$ and the $C$ atom of $\operatorname{Trp} 86\left(a_{2}\right)$ stabilizes at $3.6 \pm 0.3 \AA$, suggesting hydrophobic interactions between both rings.



Figure 3. Position of 2-PAM flanked by Tyr124 and Trp86 after 3.0 ns of MD simulation.

Such interactions could explain the permanence of 2-PAM close to Ser203-GA along the simulation.

Two other important distances also monitored in the classic simulation were the ones between the acid $\mathrm{H}$ of 2-PAM $\left(\mathrm{a}_{1}\right)$ related to the $\mathrm{N}$ atom of His447 $\left(\mathrm{a}_{3}\right)$ and to the $\mathrm{O}$ atom of Tyr337 $\left(\mathrm{a}_{2}\right)$, shown in Figure 4. Results (Figure S5, SI) show that the distances $\mathrm{a}_{1}-\mathrm{a}_{3}$ and $\mathrm{a}_{1}-\mathrm{a}_{2}$ remain, respectively, at $4.8 \pm 0.4$ and $1.9 \pm 0.2 \AA$, suggesting that 2-PAM stayed stable inside the active site of HuAChE along the MD simulation. We also monitored the average number of $\mathrm{H}$ bonds formed between 2-PAM and Tyr337 and observed two $\mathrm{H}$ bonds along the last $3.5 \mathrm{~ns}$ of simulation as shown in Figure S6, SI. This result suggests an additional reason to the stabilization of 2-PAM inside HuAChE active site.

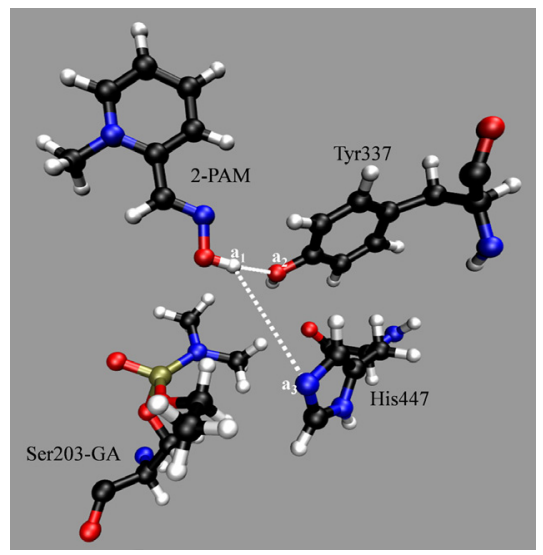

Figure 4. Position of 2-PAM related to Tyr337 and His447 after 3.0 ns of MD simulation.

\section{Hybrid molecular dynamics (QM/MM MD)}

The GROMACS/MOPAC package was validated, before performing the QM/MM MD simulations, through energy minimizations of the system, considering only 
the atoms of 2-PAM as quantum and all the remaining atoms as classic. In these calculations we also compared the semi-empirical methods AM1, PM3 and RM1 and the energy calculated and monitored was the internal energy of interaction between the non classic atoms and the system (quantum-quantum interactions plus the quantum-classic interactions minus the classic-classic interactions), called the QM/MM energy according to Groenhof and coworkers. ${ }^{35-37}$ Results in the plot of SI, Figure S7, show that with the RM1 method, the system stabilizes more quickly in this hybrid MD simulation. For this reason, RM1 was chosen to simulate the reactivation of $\mathrm{HuAChE/GA}$ by 2-PAM in this work.

After validation the GROMACS/MOPAC package was employed to perform the QM/MM MD studies of the three steps of the mechanism of reactivation of $\mathrm{HuAChE/GA}$ by 2-PAM which results are discussed below.

The protonation states $\left(\mathrm{pK}_{\mathrm{a}}\right)$ of the catalytic triad and the neighbors residues at $\mathrm{pH} 7.4$ (physiologic) calculated by the PROPKa server, ${ }^{30}$ as described in the methodology section, are presented in Table 1. Results show that, at $\mathrm{pH} 7.4$, the side chain of Glu202 should be protonated, despite its pKa value of 4.25 when isolated, and that the side chain of His447 should be preferentially in its basic form, even being amphoteric. The pKa of 2-PAM in physiologic $\mathrm{pH}$ has already been estimated and described in literature as being $7.68 .{ }^{38}$ So 2-PAM could easily donate a proton to His447 considering its major acidity related to this residue.

Table 1. Protonation state of some aminoacids of HuAChE in $\mathrm{pH} 7.4$

\begin{tabular}{cc}
\hline Aminoacid & $\mathrm{pKa}$ \\
\hline Glu202 & 10.42 \\
Glu334 & 3.89 \\
Glu450 & 7.42 \\
His447 & 4.14 \\
Tyr124 & 13.32 \\
Tyr337 & 15.09 \\
\hline
\end{tabular}

\section{Step one of the $Q M / M M M D$}

The initial coordinates for the QM/MM MD simulations where the ones corresponding to the instant 5500 ps of the classic simulation with 2-PAM positioned in a region that could favor chemical reactions, as shown in Figure 5. From this point on the letters $b_{1}$ to $b_{9}$ in Figure 5 will label the atoms of the system monitored in the three steps of the mechanism of reactivation.

In the first ps of the QM/MM simulation it was possible to observe the spontaneous protonation of the $\mathrm{O}$ atom $\mathrm{b}_{6}$ of Glu334 by the $\mathrm{H}$ atom $\mathrm{b}_{5}$ bonded to the $\mathrm{N}$ atom $\mathrm{b}_{8}$ of His447. The plot in SI, Figure S8, shows the variations on the

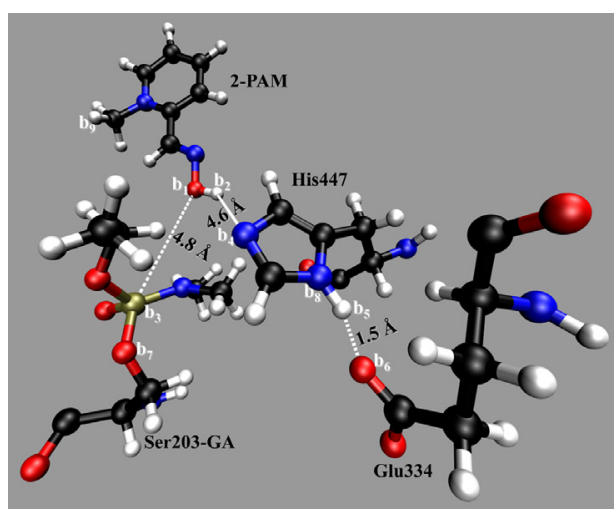

Figure 5. Frame corresponding to the instant 5500 ps of the classic simulation with 2-PAM docked inside the active site of HuAChE/GA. Letters $b_{1}-b_{9}$ represent the atoms monitored in this step.

distances: $\mathrm{b}_{8}-\mathrm{b}_{5}$ (in red) from about $1.0 \AA$ to $1.5 \AA$, suggesting the breaking of the bond $\mathrm{N}-\mathrm{H}$ of His $447, \mathrm{~b}_{6}-\mathrm{b}_{5}$ (in blue) from about $1.5 \AA$ to $1.0 \AA$, suggesting the formation of the bond $\mathrm{O}-\mathrm{H}$ on Glu334, and $\mathrm{b}_{1}-\mathrm{b}_{3}$ (in black) showing the distance variation between the $\mathrm{O}$ atom of 2-PAM and $\mathrm{P}$ atom of $\mathrm{GA}$, stabilized between 4.0 and $5.0 \AA$.

In order to check if the breaking and formation of bonds were energetically favorable, we calculated the internal energy of interaction among the quantum atoms and the remaining atoms of the system. Results shown in the plot of SI, Figure S9, suggest that between 1.0 and $2.0 \mathrm{ps}$, the energy of the reactants stabilized at about an average value of $-597.1 \pm 10.4 \mathrm{kcal} \mathrm{mol}^{-1}$. After that, at about $5.0 \mathrm{ps}$, an energy peak occurred in $-560 \mathrm{kcal} \mathrm{mol}^{-1}$, suggesting a possible TS related to the first step of reaction. Then, from 26.0 to $50.0 \mathrm{ps,} \mathrm{occurred}$ the stabilization of the energy of the products at about $-716.0 \pm 4.6 \mathrm{kcal} \mathrm{mol}^{-1}$. From these values it was possible to calculate the average energy of activation (average energy of the possible TS minus the average energy of the reactants) and also the heat of reaction (average energy of the products minus the average energy of the reactants).

The average values of energy for reactants, products, TS, activation and reaction calculated and presented in Table 2, show that after an energy barrier of about $37.1 \mathrm{kcal} \mathrm{mol}^{-1}$, the system's energy stabilizes at a value of about $118.9 \mathrm{kcal} \mathrm{mol}^{-1}$ below the energy of the reactants, suggesting the occurrence of a spontaneous reaction.

\section{Step two of the QM/MM MD}

To simulate the step two of the reaction: the protonation of anionic His447 by 2-PAM, we ploted the coordinate of reaction based on the restriction of distance between the atoms $\mathrm{b}_{1}-\mathrm{b}_{4}(\mathrm{O}$ atom of 2-PAM and $\mathrm{N}$ atom of His447) (see Figure 5). This distance was fixed at $3.5 \AA$ for 5.0 ps 
Table 2. Average energies for the first step of reaction: protonation of Glu334 by His447

\begin{tabular}{lc}
\hline Energies of & Average value $/\left(\mathrm{kcal} \mathrm{mol}^{-1}\right)$ \\
\hline Reactants & -597.1 \\
Products & -716.0 \\
Transition state & -560 \\
Reaction* & -118.9 \\
Activation** & 37.1 \\
\hline
\end{tabular}

*products: reagents; **TS: reagents.

of simulation and at $3.0 \AA$ for more 5.0 ps. After that a simulation of $50 \mathrm{ps}$ was performed without distance restriction. The starting condition of the first $5.0 \mathrm{ps}$ of this simulations was the last frame of step one with Glu334 already protonated by His447 (Figure 6) and the variation



Figure 6. Starting condition to step 2.
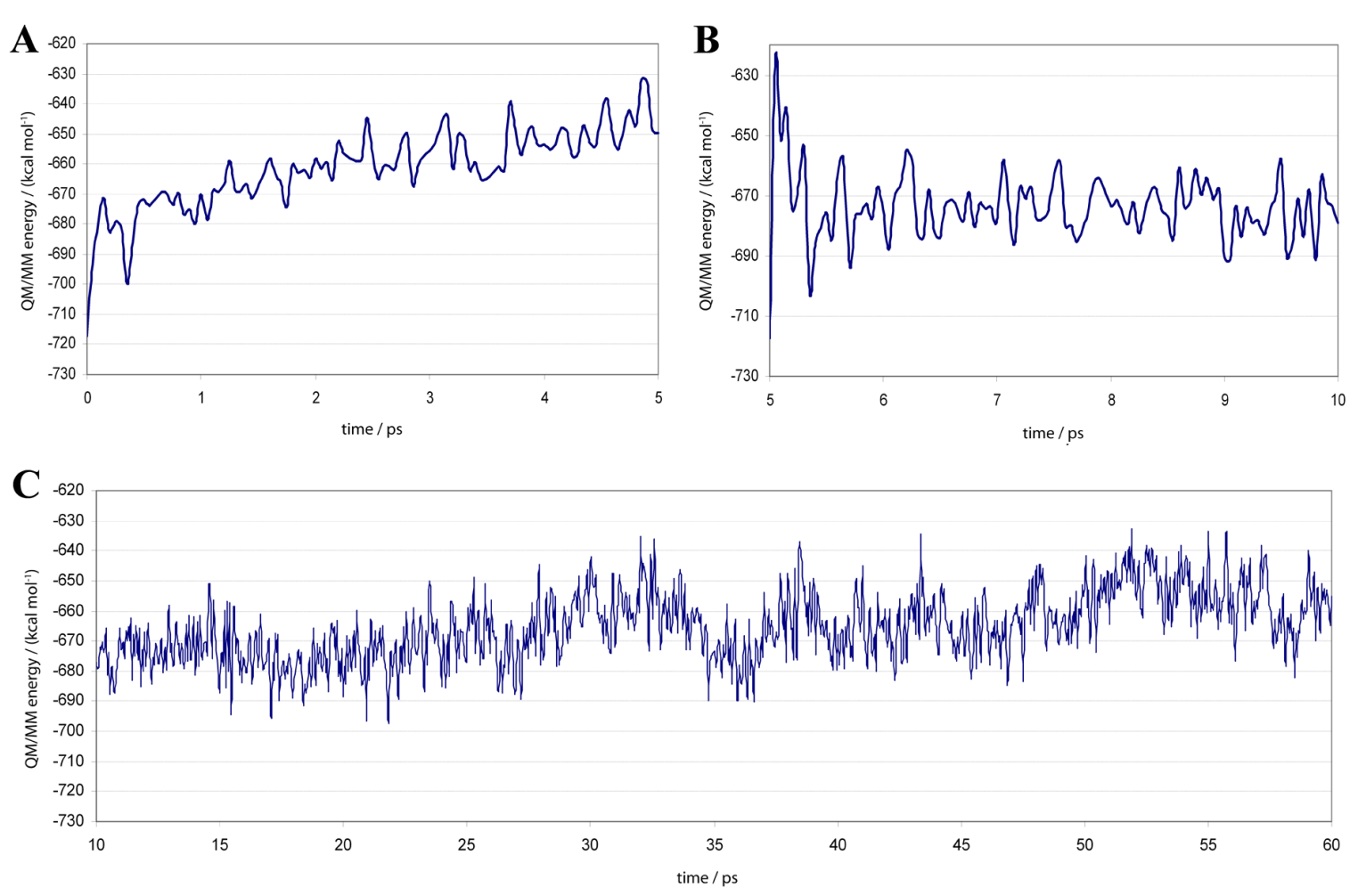

Figure 7. Energy variations in the QM/MM MD for the second step of reaction. (A) restriction at $3.5 \AA$; (B) restriction at $3.0 \AA$ and (C) without restriction.

of the QM/MM energy was calculated for each of the three simulations performed.

As shown in Figure 7(A), for the restriction at $3.5 \AA$, despite increasing, the energy stabilizes in the last ps (standard deviation in the last ps) at about $-648.40 \pm 7.2 \mathrm{kcal} \mathrm{mol}^{-1}$. For the restriction at $3.0 \AA$ [Figure 7(B)] it was observed a peak at $-624.73 \mathrm{kcal} \mathrm{mol}^{-1}$ suggesting the energy barrier of a possible TS, related to the transference of the $\mathrm{H}$ atom bonded to the $\mathrm{O}$ atom $\left(b_{1}\right)$ of 2-PAM to the $\mathrm{N}$ atom $\left(\mathrm{b}_{4}\right)$ of His 447 . When the restrictions are removed, Figure $7(\mathrm{C})$, the energy oscillates between $-680 \mathrm{kcal} \mathrm{mol}^{-1}$ and $-640 \mathrm{kcal} \mathrm{mol}^{-1}$ in the last $5.0 \mathrm{ps}$ of simulation, resulting in an average value of $-657.9 \pm 9.5 \mathrm{kcal} \mathrm{mol}^{-1}$. The calculated average values plus the maximum value of energy in the second step were, next, used to build up the plot of energy versus reaction coordinates representing the energy of the reactants, a possible TS and the products, shown in supplementary information, Figure S10.

Monitoring the energy variation of distances between $b_{1}-b_{2}$ and $b_{2}-b_{4}$, it is possible to notice that a transference of the acid $\mathrm{H}$ from 2-PAM to His447 really happens. This fact is illustrated by the stabilization of the distance $b_{2}-b_{4}$, at about 1.0 ̊ shown in Figure 8. Its also possible to see that in the last $50 \mathrm{ps}$, with no restriction in the distance $\mathrm{b}_{1}-\mathrm{b}_{4}, 2$-PAM stays quite close to GA and the distance $\mathrm{b}_{1}-\mathrm{b}_{3}$ stabilizes at about $5.0 \AA$ from 40 ps. 




Figure 8. Variation of the distances $b_{1}-b_{2}, b_{1}-b_{3}$ and $b_{2}-b_{4}$, with time.

\section{Step three of the $Q M / M M M D$}

To study the third step of the reactivation reaction, six successive QM/MM MD simulations of $5.0 \mathrm{ps}$ each where performed initially, starting with the last frame of the second step. In the first 5 simulations the distance $\mathrm{b}_{1}-\mathrm{b}_{3}$, was restricted, respectively at $4.0 \AA$, $3.5 \AA$, $3.0 \AA$, $2.5 \AA$ and $2.0 \AA$ and, in the sixth simulation, the distances $b_{1}-b_{3}$ and $b_{3}-b_{7}$ were restricted at $2.0 \AA$ in order to allow the stabilization of the possible TS with a bipyramid trigonal geometry (Figure 9). Keeping the restrictions above, we made new distance restrictions, this time to the bond $b_{4}-b_{7}$ (Figure 10), respectively at $5.5 \AA, 5.0 \AA, 4.5 \AA, 4.0 \AA$ and $3.5 \AA$ and performed additional QM/MM MD simulations of 5.0 ps for each restriction. Finally, after running 25 ps of simulations with distance restrictions, there were performed more $50 \mathrm{ps}$ of simulation without distance restrictions, totalizing $75 \mathrm{ps}$ of QM/MM MD simulations. The energy of this step was calculated and added to the energy obtained for the $30 \mathrm{ps}$ of the former simulations, affording the energetic profile of a chemical reaction for the 105 ps of simulation, as shown in the plot of SI, Figure S11, where the QM/MM energies of the reactants are, between -650 and $-600 \mathrm{kcal} \mathrm{mol}^{-1}$, the possible TS, at about $-500 \mathrm{kcal} \mathrm{mol}^{-1}$, and the products, oscillating between -675 and $-625 \mathrm{kcal} \mathrm{mol}^{-1}$. The distances $\mathrm{b}_{2}-\mathrm{b}_{4}, \mathrm{~b}_{2}-\mathrm{b}_{7}, \mathrm{~b}_{1}-\mathrm{b}_{3}$, $b_{3}-b_{7}$ and $b_{4}-b_{9}$, which variation could favor the occurrence of chemical reactions, were monitored from 30 ps to 105 ps. It is important to notice that the gap from 30 to $55 \mathrm{ps}$ corresponds to the region where the distance $\mathrm{b}_{4}-\mathrm{b}_{7}$ varies while the distances $b_{1}-b_{3}$ and $b_{3}-b_{7}$ are restricted to $2.0 \AA$. From 55 ps all restrictions were removed. The variations of distances $\mathrm{b}_{2}-\mathrm{b}_{4}, \mathrm{~b}_{2}-\mathrm{b}_{7}, \mathrm{~b}_{1}-\mathrm{b}_{3}, \mathrm{~b}_{3}-\mathrm{b}_{7}$ and $\mathrm{b}_{4}-\mathrm{b}_{9}$, along time are shown in Figures 11 to 13.

As can be seen in Figure 11, soon after the restriction at $3.5 \AA$ to the distance $\mathrm{b}_{4}-\mathrm{b}_{7}$ (between 50 and $55 \mathrm{ps}$ ), the proton $\left(b_{2}\right)$ is rapidly transferred to the $\mathrm{O}$ atom $\left(b_{7}\right)$ of Ser 203 and does not bind back to the $\mathrm{N}$ atom $\left(\mathrm{b}_{4}\right)$ when all the restrictions are removed, at $55 \mathrm{ps}$. In fact the distance $\mathrm{b}_{2}-\mathrm{b}_{7}$ stabilizes at about

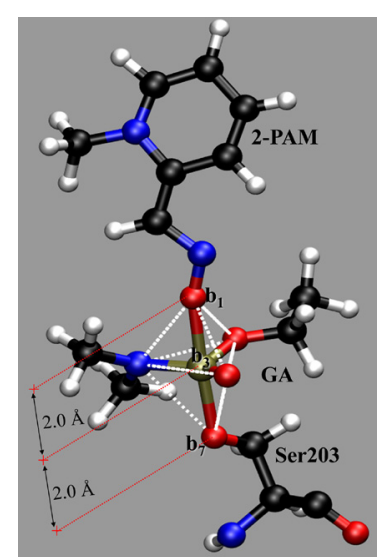

Figure 9. Bipyramid trigonal geometry of the complex 2-PAM/GA/ Ser203.

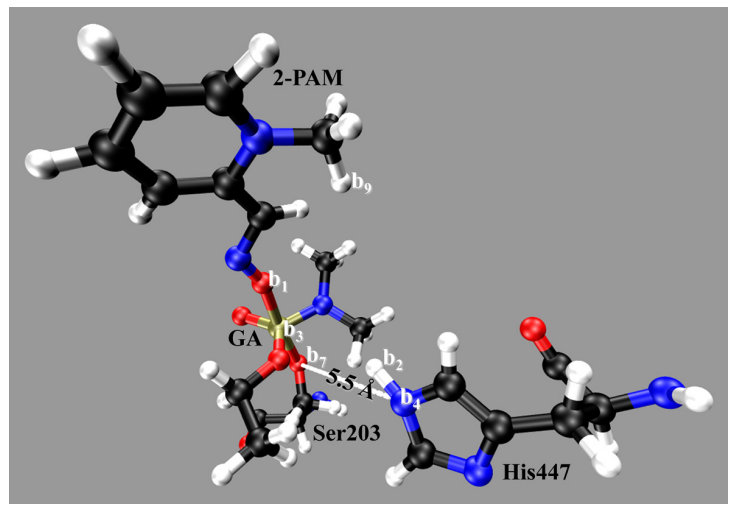

Figure 10. Restriction of the bond $b_{4}-b_{7}$ at $5.5 \AA$.

$1.0 \AA$, characterizing the formation of a new bond, while the distance $\mathrm{b}_{4}-\mathrm{b}_{7}$ rises from $1.0 \AA$ to about $6.0 \AA$, suggesting the breaking down of the bond $b_{4}-b_{7}$.

For the distance variations related to the $\mathrm{P}$ atom of GA $\left(b_{3}\right)$, the $\mathrm{O}$ atom of 2-PAM $\left(b_{1}\right)$ and the $\mathrm{O}$ atom of Ser203 $\left(b_{7}\right)$ (see Figure 12), it is possible to notice that between 55 and $66 \mathrm{ps,}$ already with no restrictions in distance, $b_{3}$ approximates to $b_{1}$ and moves away from $b_{7}$. Besides, from $66 \mathrm{ps}$ on, the distance $\mathrm{b}_{1}-\mathrm{b}_{3}$ stays at about $1.75 \AA$ (the length of a covalent $\mathrm{O}-\mathrm{P}$ bond) suggesting that $\mathrm{HuAChE}$ was effectively reactivated.

Other important result is observed in Figure 13 where it is possible to see the occurrence of a natural protonation of the $\mathrm{N}$ atom $\left(b_{4}\right)$ of His 447 by one of the methyl $\mathrm{H}$ atoms of 2-PAM $\left(b_{9}\right)$ without any distance restriction. From 55 ps of simulation on, $b_{9}$ approximated to $b_{4}$ and stabilized at the distance of $1.0 \AA$ (at $66 \mathrm{ps}$ ), suggesting the formation of a $\mathrm{H}$ bond.

Characterization of the true saddle points and intrinsic reaction coordinates for each reaction step of the QM/MM MD simulation

In the first step of the saddle point characterization, we chose as starting conditions, only the coordinates of 




Figure 11. Variations of the distances $b_{2}-b_{4}$ and $b_{2}-b_{7}$ along the last 75 ps of simulation.

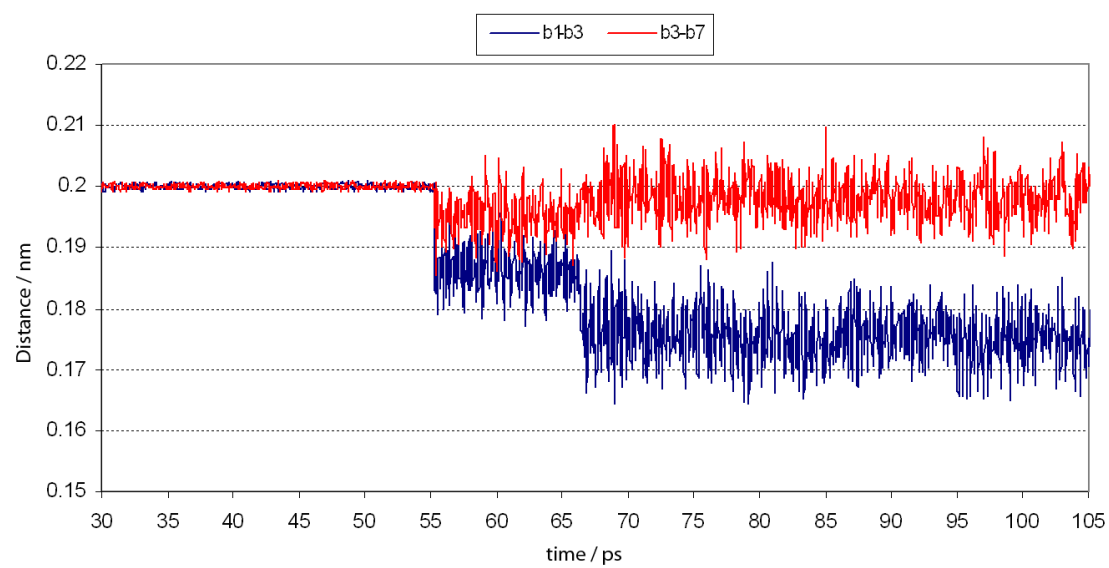

Figure 12. Variations of the distances $b_{1}-b_{3}$ and $b_{3}-b_{7}$ along the last $75 \mathrm{ps}$ of simulation.

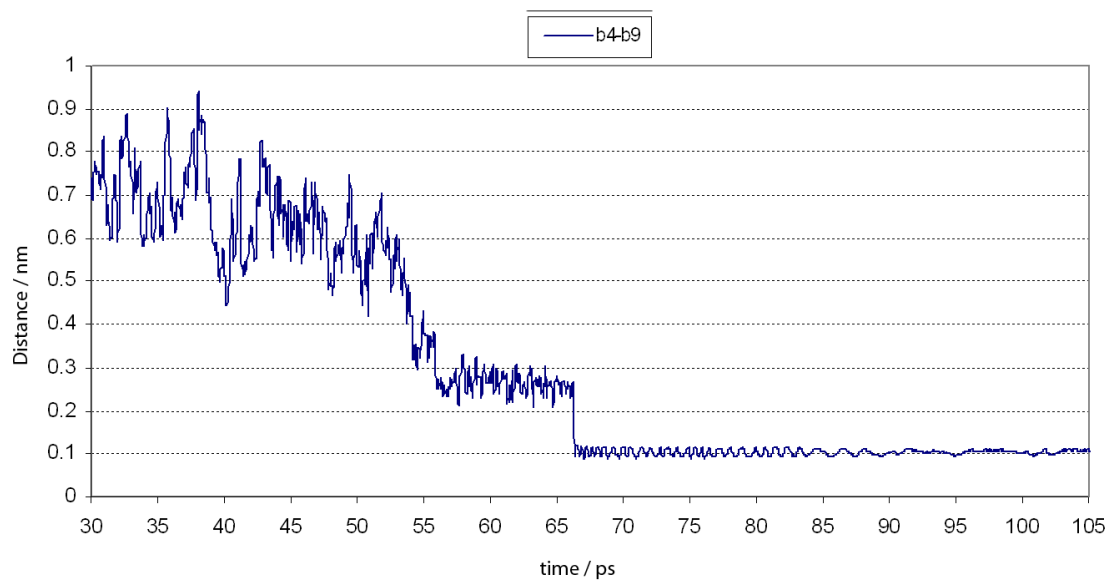

Figure 13. Variations of the distances $\mathrm{b}_{4} \mathrm{~b}_{9}$ along the last $75 \mathrm{ps}$ of simulation.

the quantum atoms of His447 and Glu334 at the moment of the proton transference from the $\mathrm{N}$ atom $\delta$ of the His447 to Ser203, in the first step of the QM/MM MD simulation. From the calculation of the TS we obtained an unique imaginary frequency of $2,216 \mathrm{i} \mathrm{cm}{ }^{-1}$. Therefore we performed, also, using RM1, the calculation of the IRC in order to check if there were connection among reactants, TS and products. Results showed that the TS obtained was 
Table 3. Relative energy for reagents, TSs and products, calculated by IRC and RM1 methods for each reaction step

\begin{tabular}{|c|c|c|c|}
\hline & Reactants / (kcal mol-1) & $\mathrm{TS} /\left(\mathrm{kcal} \mathrm{mol}^{-1}\right)$ & Products / $\left(\mathrm{kcal} \mathrm{mol}^{-1}\right)$ \\
\hline First reaction step & 3.34 & 13.01 & 0.00 \\
\hline Second reaction step & 0.00 & 0.30 & -33.51 \\
\hline Third reaction step & 6.70 & 17.46 & 0.00 \\
\hline Unexpected reaction step & 0.00 & 0.18 & -21.77 \\
\hline
\end{tabular}

characterized as a true saddle point and that this reaction in fact occurs (see Table 3 ) with an energetic barrier reactantsproducts of $9.67 \mathrm{kcal} \mathrm{mol}^{-1}$.

In step 2, the occurrence of the proton transference from the $\mathrm{OH}$ of 2-PAM to the $\mathrm{N}$ atom $\varepsilon$ of His 447 was favored by the participation of Glu334. The coordinates of these 03 molecules were extracted from the second step of the $\mathrm{QM} / \mathrm{MM}$ simulation, exactly at the moment of the proton transference from 2-PAM to the basic $\mathrm{N}$ of His447. The calculation of TS to this reaction step was performed and showed that there was an unique imaginary frequency of $1,185 \mathrm{i} \mathrm{cm}^{-1}$ in the hessian matrix, characterizing this point as a true saddle point. Besides, the IRC results (Table 3) evidenced connections among reactants, TS and products and that Glu334 contributed with a small energetic barrier, of only $0.3 \mathrm{kcal} \mathrm{mol}^{-1}$, that favored the occurrence of one more exotermic reaction with a reaction heat of $-33.51 \mathrm{kcal} \mathrm{mol}^{-1}$. Results for step 2 are, also, shown in Table 3.

To the step 3 we used, as initial conditions, the coordinates of the bipyramid trigonal complex of 2-PAM/ GA/Ser203 (see Figure 9) plus the coordinates of His447 at the moment of proton donation to the $\mathrm{O}$ atom of Ser203. The TS was confirmed by the observation of an unique imaginary frequency at $2,345 \mathrm{i} \mathrm{cm} \mathrm{cm}^{-1}$ and the IRC evidenced connections among reactants, TS and products, characterizing the TS as a true saddle point. In this step, the value of the activation energy $\left(10.76 \mathrm{kcal} \mathrm{mol}^{-1}\right)$ was close to the value obtained in the first step of the reaction and the value of the heat of reaction was of $-6.7 \mathrm{kcal} \mathrm{mol}^{-1}$, suggesting that the third step of reaction is, also, exothermic.

In the last step of reaction, the donation of a proton from the methyl group of 2-PAM to His447, the starting conditions to the calculation of TS and IRC were the coordinates corresponding to the moment of donation. Results showed that, for this step, despite the fact that the breaking down of a bond $\mathrm{C}-\mathrm{H}$ is not usual in organic chemistry, a well characterized TS with frequency of $737 \mathrm{i} \mathrm{cm}^{-1}$ was observed. Besides, their validation as a true saddle point was performed by IRC (see Table 3 ). The calculated reaction heat was of $-21.77 \mathrm{kcal} \mathrm{mol}^{-1}$, suggesting that this reaction liberates heat and imply in a smaller energetic spending than the former step, with an energetic barrier of only $0.18 \mathrm{kcal} \mathrm{mol}^{-1}$ (see Table 3 ).
The IRC and TS calculations for each reaction step showed that all of them are spontaneous and effectively occur because all the possible TS were characterized as true saddle points and, also, because the four steps occurred in the direction of the products formation. Besides, all the imaginary frequencies obtained were unique and intense when compared with other values of the hessian matrix.

An unusual result observed in the present work was the spontaneous transference of a proton from the methyl group of 2-PAM to His 447 in the last step of reaction. This kind of reaction, however, is very similar to the proton transference involving ylide species already described in literature some decades ago. ${ }^{39,40}$

Another questionable issue of this work is the use of semi-empirical methods to the calculations of TSs and IRCs. This methodology, however, have already been discussed in literature in our most recent paper ${ }^{6}$ in which we showed that the same TS can be obtained using the semi-empirical methods RM1 and PM6 and the most robust method DFT/B3LYP 6-31G(d,p).

Finally, it was possible in this work to put together information from the QM/MM MD simulation and from the characterization of the TSs as true saddle points in order to propose a feasible mechanism for the reaction of reactivation, by 2-PAM, of HuAChE inhibited by the neurotoxic agent tabun, as shown in Figure 14.

\section{Conclusions}

The classic MD simulation step applied on the coordinates of the 3D model of HuAChE inhibited by tabun proposed in a former study, ${ }^{5}$ showed that 2-PAM is able to penetrate the active site gorge of $\mathrm{HuAChE}$ and stabilizes itself close to the catalytic triad. This result corroborates the classic MD simulation as a good computational tool to predict qualitatively the energies involved and the HuAChE-oxime interaction.

The computational package GROMACS/MOPAC/RM1 implemented in this work made possible the achievement of an energy minimum with a smaller number of steps and, also, the use of a larger number of quantum atoms (up to 500) in the system and showed to be satisfactory in 


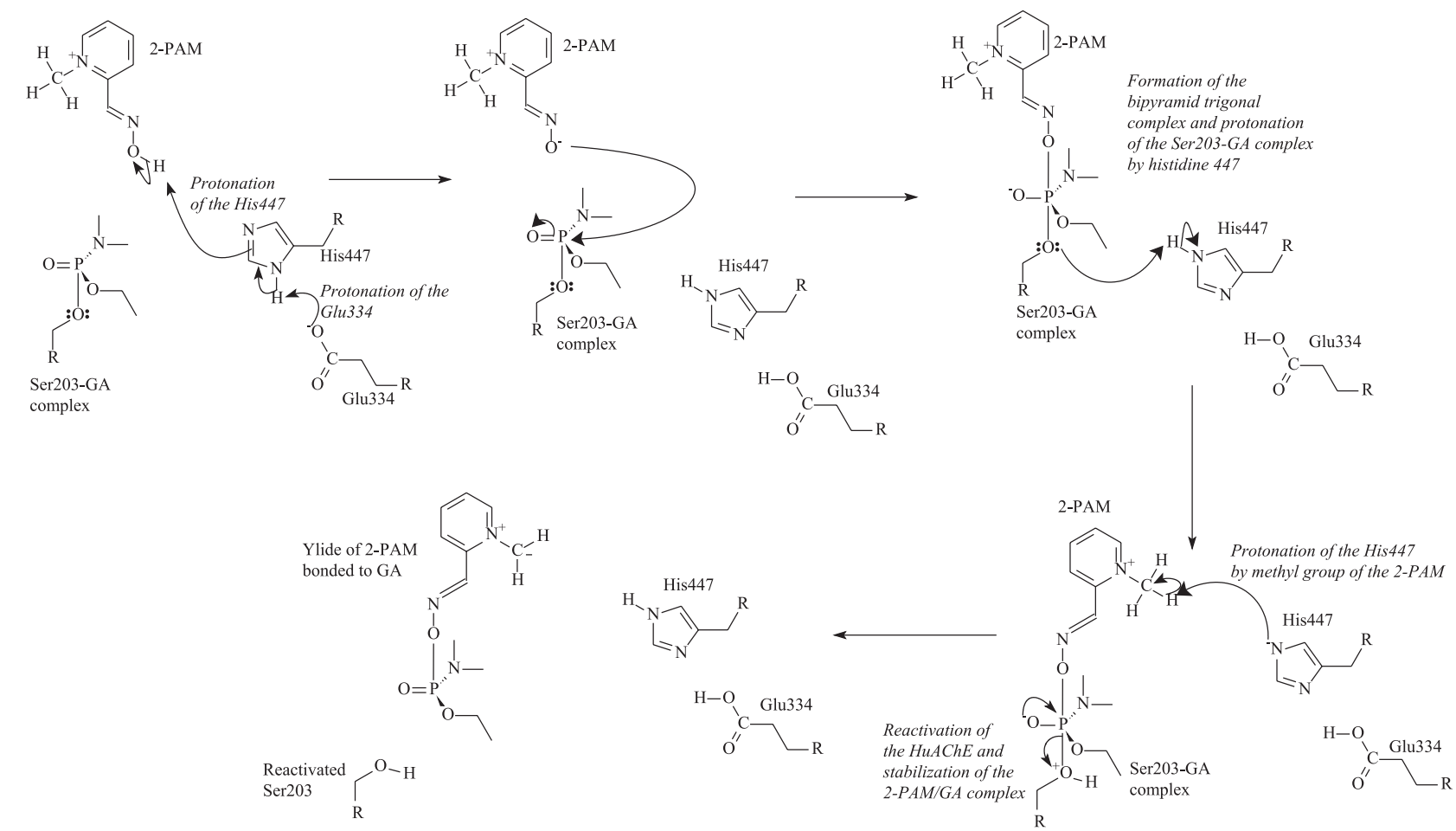

Figure 14. Reactivation mechanism of HuAChE inhibited by GA proposed in this work.

the description of the energies involved in each one of the steps of the reactivation mechanism.

The use of the hybrid QM/MM MD made possible the study of the breaking and formation of chemical bonds, i.e, the proposition of chemical reactions in an enzymatic medium, that would not be possible only with classic MD simulations.

The characterization of the possible TS suggested by QM/MM MD using the semi-empirical method RM1 and the IRC as true saddle points, proved to be able to show connections among reactants, TS and products in each reaction step of the HuAChE reactivation, making possible the proposition of a feasible via for the HuAChE reactivation by 2 -PAM.

\section{Supplementary Information}

Supplementary data are available free of charge at http://jbcs.sbq.org.br, as PDF file.

\section{Acknowledgments}

We are grateful to IME, CNPq, FAPERJ and CAPES/ PRODEFESA for funding this work.

\section{References}

1. Delfino, R. T.; Ribeiro, T. S.; Figueroa-Villar, J. D.; J. Braz. Chem. Soc. 2009, 20, 407.
2. Ekstrom, F. J.; Astot, C.; Pang, Y. P.; Clin. Pharmacol. Ther. 2007, $82,282$.

3. Worek, F.; Aurbek, N.; Koller, M.; Becker, C.; Eyer, P.; Thiermann, H.; Biochem. Pharmacol. 2007, 73, 1807.

4. Castro, A. T.; Figueroa-Villar, J. D.; Int. J. Quantum Chem. 2002, $89,135$.

5. Gonçalves, A. S.; França, T. C. C.; Wilter, A.; Figueroa-Villar, J. D.; J. Braz. Chem. Soc. 2006, 17, 968.

6. Gonçalves, A. S.; França, T. C. C.; Figueroa-Villar, J. D.; Pascutti, P. G.; J. Braz. Chem. Soc. 2010, 21, 179.

7. Delfino, R. T.; Figueroa-Villar, J. D.; J. Phys. Chem. B 2009, 113, 8402 .

8. Smirnova, O. I.; Gurina, E. I.; Zhigalova, L. V.; Arestova, L. S.; Farmakologiya I Toksikologiya 1975, 38, 467.

9. Bay, E.; Krop, S.; Yates, L. F.; Proc. Soc. Exp. Biol. Med. 1958, 98 , 107.

10. Kuča, K.; Cabal, J.; Jun, D.; Kassa, J.; Bartosova, L.; Kunesova, G.; J. Appl. Toxicol. 2005, 25, 296.

11. Nemukhin, A. V.; Lushchekina, S. V.; Bochenkova, A. V.; Golubeva, A. A.; Varfolomeev, S. D.; J. Mol. Mod. 2008, 14, 409.

12. Lu, Z. Y.; Zhang, Y. K.; J. Chem. Theory Comput. 2008, 4, 1237.

13. Shoeib, T.; Ruggiero, G. D.; Siu, K. W. M.; Hopkinson, A. C.; Williams, I. H.; J. Chem. Phys. 2002, 117, 2762.

14. Ramalho, T. C.; França, T. C. C.; Rennó, M. N.; Guimarães, A. P.; Cunha, E. F. F.; Kuča, K.; Chem.-Biol. Interact. 2010, $185,73$.

15. Aqvist, J.; Warshel, A.; Chem. Rev. 1993, 93, 2523. 
16. Ramalho, T. C.; Caetano, M. S.; da Cunha, E. F. F.; Souza, T. C. S.; Rocha, M. V. J.; J. Biomol. Struct. Dyn. 2009, 27, 195.

17. Kwasnieski, O.; Verdier, L.; Malacria, M.; Derat, E.; J. Phys. Chem. B 2009, 113, 10001.

18. Ramalho, T. C.; da Cunha, E. F. F.; de Alencastro, R. B.; J. Phys.: Condens. Matter 2004, 16, 6159.

19. Van Der Spoel, D.; Lindahl, E.; Hess, B.; Groenhof, G.; Mark, A. E.; Berendsen, H. J.; J. Comput. Chem. 2005, 26, 1701.

20. Jorgensen, W. L.; Maxwell, D. S.; Tirado-Rives, J.; J. Am. Chem. Soc. 1996, 118, 11225.

21. Kahn, K.; Bruice, T. C.; J. Comput. Chem. 2001, 23, 977.

22. Brenamann, C. M.; Wiberg, K. B.; J. Comput. Chem. 1990, 11, 361.

23. Schmidt, M. W.; Baldridge, K. K.; Boatz, J. A.; Elbert, S. T.; Gordon, M. S.; Jensen, J. H.; Koseki, S.; Matsunaga, N.; Nguyen, K. A.; Su, S. J.; Windus, T. L.; Dupuis, M.; J.Comput.Chem. 1993, 14, 1347.

24. Neumann, M.; J. Chem. Phys. 1986, 85, 1567.

25. Elhawary, M. E.; Wellon, O. K.; IEEE Trans. Power Apparatus Systm. 1982, 101, 854.

26. Lootsma, F. A.; Lecture Notes in Economics and Mathematical Systems 1991, 367, 1.

27. Darden, T.; York, D.; Pedersen, L.; J. Chem. Phys. 1993, 98, 10089.

28. Essmann, U.; Perera, L.; Berkowitz, M. L.; Darden, T.; Lee, H.; Pedersen, L. G.; J. Chem. Phys. 1995, 103, 8577.

29. Li, H.; Robertson, A. D.; Jensen, J. H.; Proteins 2005, 61, 704.
30. Bas, D. C.; Rogers, D. M.; Jensen, J. H.; Proteins 2008, 73, 765.

31. Delano, W. L.; DeLano Scientific; Palo Alto, CA, USA, 2002.

32. Delano, W. L.; Brinberg, S.; DeLano Scientific LLC; San Francisco, CA, 2004.

33. Morokuma, K.; Dapprich, S.; Komaromi, I.; Froese, R. D.; Holthausen, M.; Musaev, D. G.; Byun, S.; Khoroshun, S.; Abstracts of Papers of the American Chemical Society 1997, 214, 74.

34. Morokuma, K.; Froese, R. D.; Dapprich, S.; Komaromi, I.; Khoroshun, D.; Byun, S.; Musaev, D. G.; Emerson, C. L.; Abstracts of Papers of the American Chemical Society 1998, 215, U218.

35. Boggio-Pasqua, M.; Robb, M. A.; Groenhof, G.; J. Am. Chem. Soc. 2009, 131, 13580.

36. Groenhof, G.; Schafer, L. V.; Boggio-Pasqua, M.; Grubmuller, H.; Robb, M. A.; J. Am. Chem. Soc. 2008, 130, 3250.

37. Donnini, S.; Groenhof, G.; Wierenga, R. K.; Juffer, A. H.; Proteins: Struct., Funct., Bioinf. 2006, 64, 700.

38. Gray, A. P.; Drug Metab. Rev. 1984, 15, 557.

39. Cope, A. C.; Lebel, N. A.; Moore, W. R.; Moore, P. T.; J. Am. Chem. Soc. 1961, 83, 3861.

40. Cope, A. C.; Mehta, A. S.; J. Am. Chem. Soc. 1963, 85, 1949.

Submitted: April 10, 2010

Published online: September 30. 2010 


\title{
Molecular Dynamics Simulations and QM/MM Studies of the Reactivation by 2-PAM of Tabun Inhibited Human Acethylcolinesterase
}

\author{
Arlan da Silva Gonçalves, *a Tanos C. C. França, ${ }^{b}$ \\ José D. Figueroa-Villar ${ }^{b}$ and Pedro G. Pascuttic \\ ${ }^{a}$ Rua Sete de Setembro, 117, Centro, 25020-190 Duque de Caxias-RJ, Brazil \\ ${ }^{b}$ Seção de Engenharia Química, Instituto Militar de Engenharia, Praça General Tibúrcio, 80, \\ 22290-270 Rio de Janeiro-RJ, Brazil \\ 'Instituto de Biofísica Carlos Chagas Filho, CCS, Avenida Carlos Chagas Filho, 373, Bloco D, \\ Sala D1-030, Ilha do Fundão, Universidade Federal do Rio de Janeiro, \\ 21941-900 Rio de Janeiro-RJ, Brazil
}

\section{Compilation of GROMACS with MOPAC and RM1 to Create GROMACS QM/MM}

The compilation of GROMACS 3.3.31 with MOPAC and RM1 (Recife Model One) ${ }^{2}$ method was performed by changing the AM1 atomic parameters values presented at the MOPAC source file block.f for the hydrogen, carbon, nitrogen, oxygen, phosphorus, sulfur, fluorine, chlorine, bromine and iodine atoms by RM1 parameters, proposed by Rocha and collaborators. ${ }^{2}$ Then the package compilation (GROMACS+MOPAC+RM1) was made according to the following procedure: (i) GROMACS 3.3.31 was downloaded from http://www.gromacs.org and extracted into the GROMACS folder; (ii) The MOPAC 7 source was downloaded from http://openmopac.net/Downloads/ Downloads.html, and also extracted to the GROMACS folder; (iii) The GROMACS routines modified by Groenhof, ${ }^{3}$ gmxmop.f and decart.f were copied to the
GROMACS folder in order to replace the mopac.f, moldat.f and deriv.f sources and all other codes were used to create object files with the FORTRAN 77 compiler (f77 -O3 -c *.f); (iv) All the objects (*.o) were collected into the libmopac.a library: ar rcv libmopac.a *.o and ranlib libmopac.a; (v) The libmopac.a library was moved to the GROMACS folder and the GROMACS+MOPAC+RM1 package was configured with the flags: CPPFLAGS=-DUSE_MOPAC, LIBS=-lmopac and LDFLAGS=-L\$PWD.

\section{References}

1. Van Der Spoel, D.; Lindahl, E.; Hess, B.; Groenhof, G.; Mark, A. E.; Berendsen, H. J.; J. Comput. Chem. 2005, 26, 1701.

2. Rocha, G. B.; Freire, R. O.; Simas, A. M.; Stewart, J. J. P.; J. Comput. Chem. 2006, 27, 1101.

3. Groenhof, G.; Bouxin-Cademartory, M.; Hess, B.; De Visser, S. P.; Berendsen, H. J. C.; Olivucci, M.; Mark, A. E.; Robb, M. A.; J. Am. Chem. Soc. 2004, 126, 4228. 


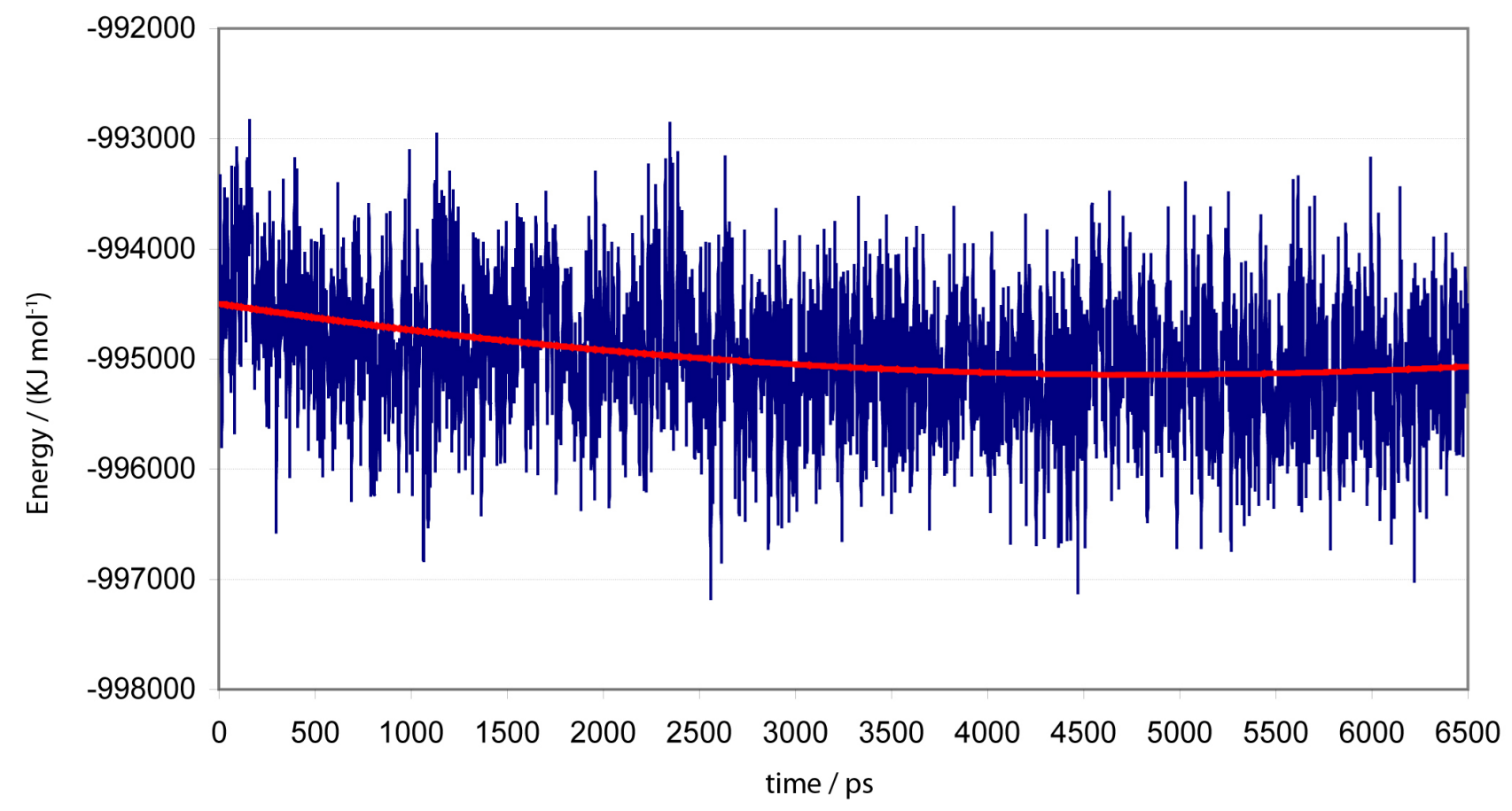

Figure S1. Total energy variation for the system HuAChE/2-PAM/GA along the $6.5 \mathrm{~ns}$ of classic MD simulation. The quadratic regression is indicated by the red line.

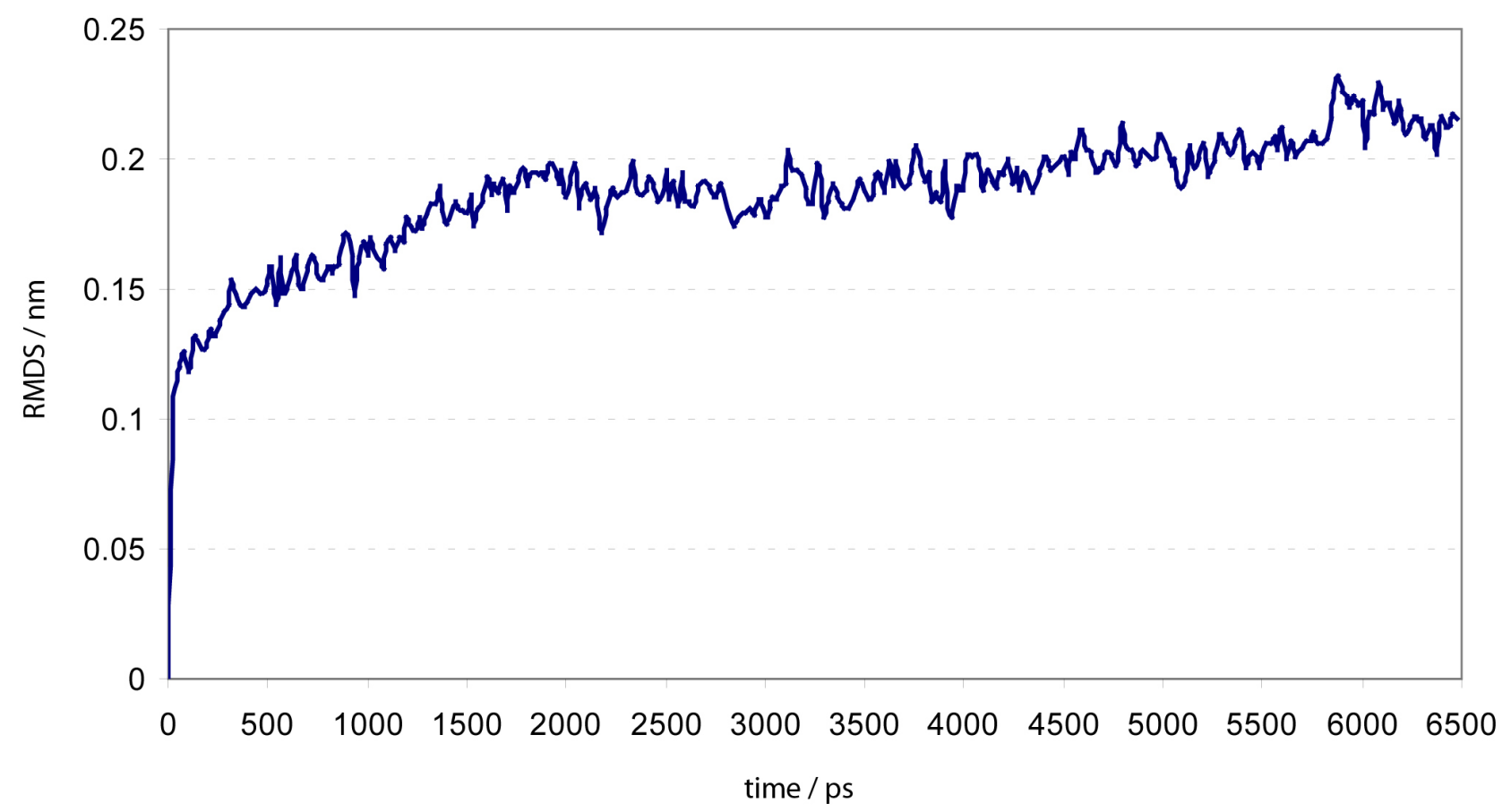

Figure S2. Temporal RMSD for the system HuAChE/GA/2-PAM. 




Figure S3. Distance variation between the acid $\mathrm{O}$ atom of 2-PAM and the $\mathrm{P}$ atom of GA along the MD simulation.



Figure S4. Variations of distances among atoms of Tyr124, 2-PAM and Trp86 along the MD simulation. 


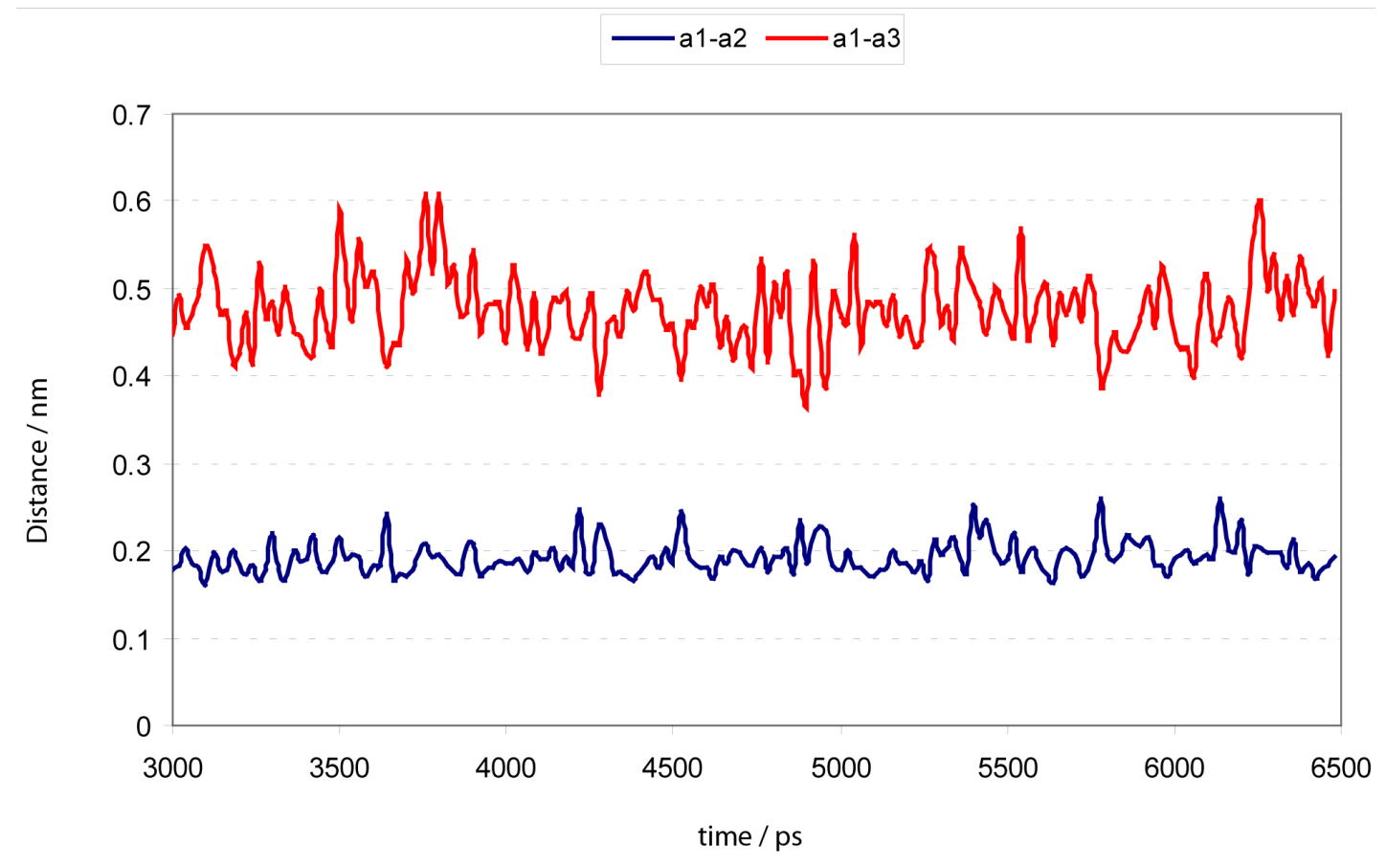

Figure S5. Variations of distances among atoms of Tyr337, 2-PAM and His447 along the MD simulation.

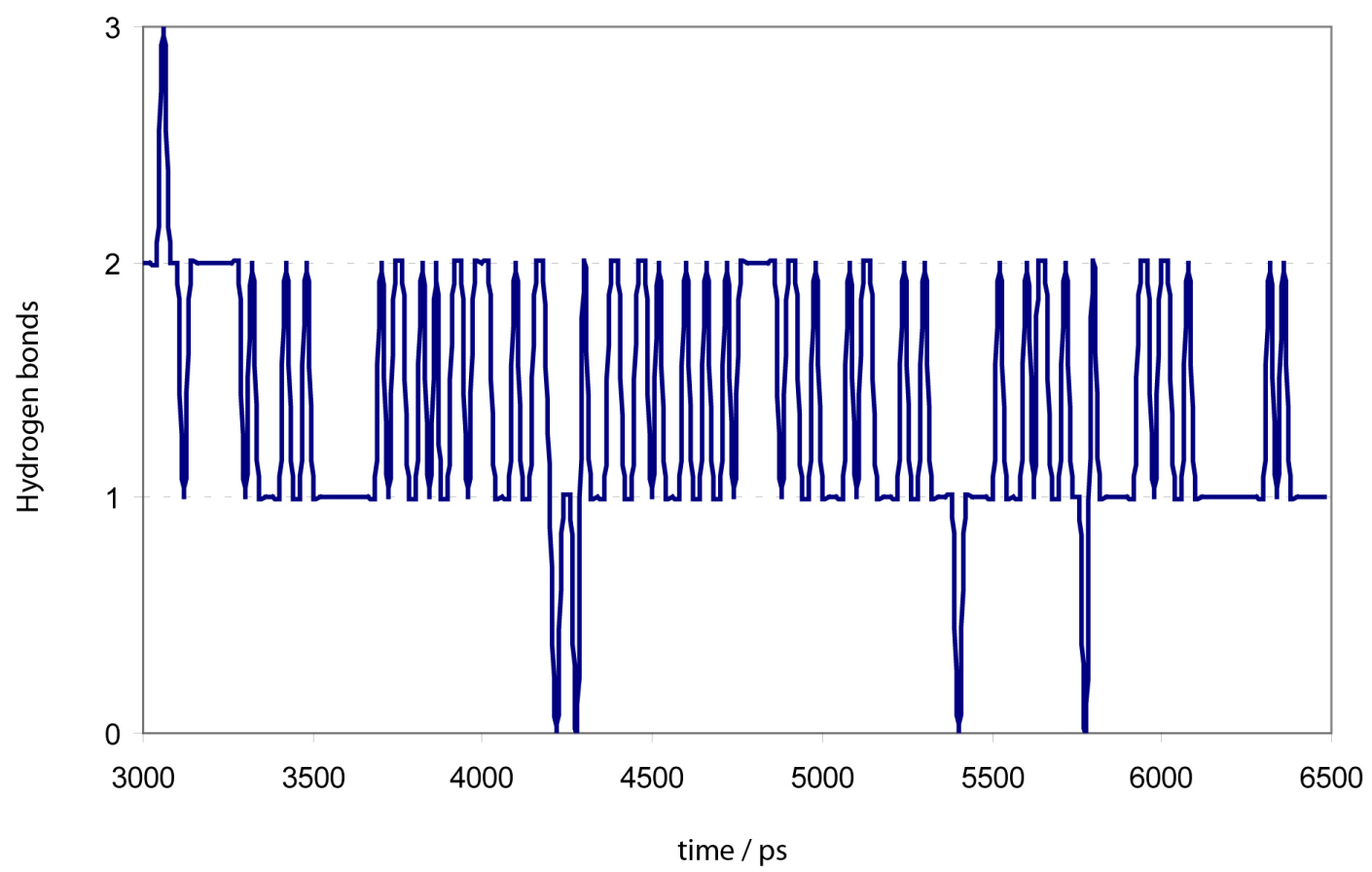

Figure S6. Average number of Hbonds formed between 2-PAM and Tyr337 along the simulation. 




Figure S7. Energy minimization of HuAChE/GA by QM/MM with different semi-empirical methods.
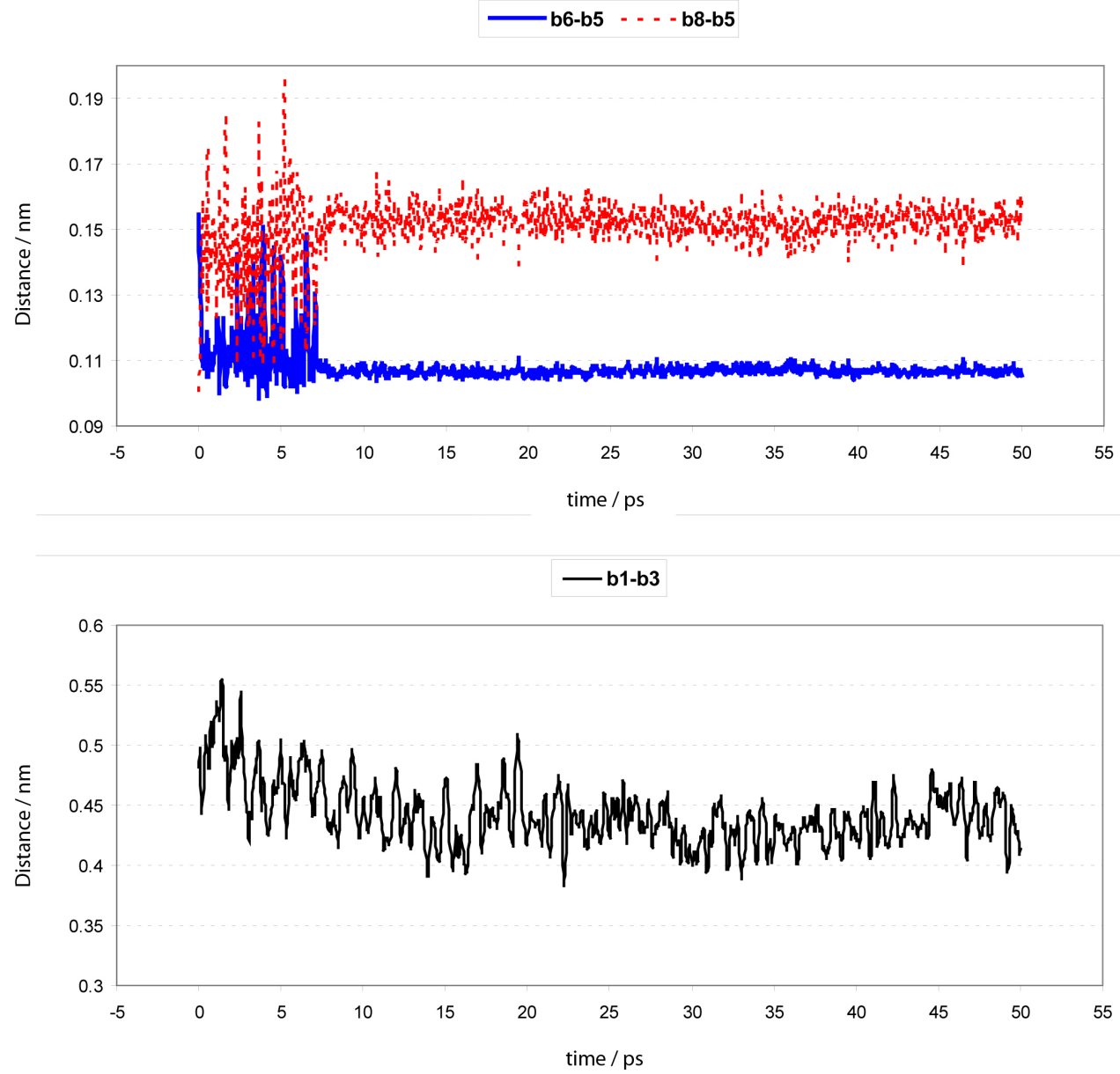

Figure S8. Variation of distances $\mathrm{b}_{6}-\mathrm{b}_{5}, \mathrm{~b}_{8}-\mathrm{b}_{5}$ and $\mathrm{b}_{1}-\mathrm{b}_{3}$, with time. 




Figure S9. Variation of the QM/MM energy for the first step of reaction.



Figure S10. Reaction coordinates proposed to the second step of reaction. 


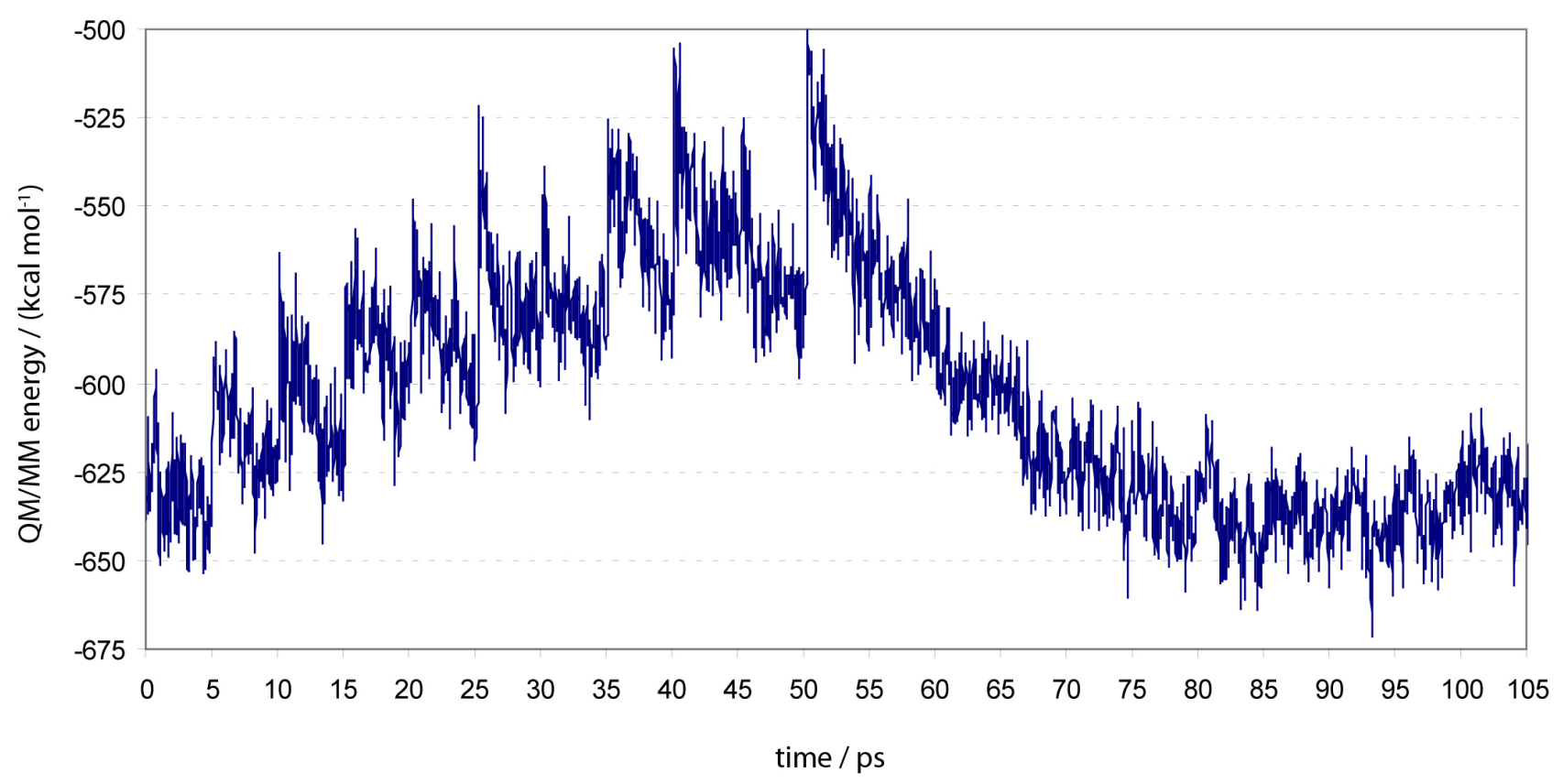

Figure S11. Energy profile for the 105 ps of QM/MM MD simulation. 